\title{
Changing mortality patterns in Nauruans: an example of epidemiological transition
}

\author{
M SCHOONEVELDT ${ }^{1}$, T SONGER ${ }^{2}$, P ZIMMET, ${ }^{1}$ AND K THOMA ${ }^{3}$ \\ From WHO Collaborating Centre for the Epidemiology of Diabetes Mellitus, ${ }^{1}$ Lions International Diabetes \\ Institute, Melbourne, Australia; Diabetes Research Center of Children's Hospital of Pittsburgh, ${ }^{2}$ PA, USA; and \\ Nauru General Hospital, ${ }^{3}$ Nauru
}

SUMMARY An analysis of mortality data for the years 1982-5 was carried out for the Micronesian population (aged 15 years and over) of the central Pacific Island, Nauru. Among males, the most common causes of death were circulatory system disorders $(33.3 \%)$, accidents $(25 \cdot 2 \%)$, and diabetes mellitus $(12 \cdot 1 \%)$. The majority of accidents occurred in the 15-34 year age group and involved motor vehicles. Among females, neoplasms (almost all lung and cervix) $(22.4 \%)$, circulatory system disorders $(20.7 \%)$, and diabetes mellitus $(17 \cdot 2 \%)$ were the most common causes of death. When accidents are excluded, $59.4 \%$ of deaths were in persons with diabetes. Compared with Australia, mortality rates in almost all age groups were at least five times higher for males and females for a comparable period. Nauruan life expectancy (39.5 years for men and 48.5 years for women) is one of the lowest in the world. These data confirm the high mortality associated with diabetes mellitus in Nauruans as evidenced in earlier studies. Modernisation of this society through the affluence acquired by the mining of phosphate has led to serious public health problems relating to non-communicable diseases so that the mortality trends now mirror those of developed societies.

It has been suggested that the changing patterns of disease and mortality in Third World populations are related to their economic and social development. Under existing epidemiological models, ${ }^{12}$ the initial exposure of traditional populations to western civilisation led to epidemics of infectious diseases resulting in high mortality rates. Continued economic and social development resulted in a shift in lifestyle practices from traditional to modern, along with improved public health, reducing the mortality from communicable disease but, somewhat paradoxically, introducing risk factors for non-communicable diseases. Exposure to these risk factors over time has in turn led to the emergence of "western diseases" and associated mortality in these developing populations.

Analysis of previous mortality reports in the Pacific island of Nauru ${ }^{3-7}$ suggests that a shift in mortality patterns has occurred and may be related to exposure to western practices. Infectious diseases were the major cause of death until the end of the 1950s, and mortality from diabetes and coronary heart disease was slight. ${ }^{67}$ Subsequently, mortality from motor vehicle accidehts, cardiovascular disease, and diabetes has overtaken infectious diseases as the main cause of mortality. ${ }^{457}$
The present study reports on the mortality profile of this unique communty from 1982 to 1985 in order to evaluate the continuing influence of western lifestyle change on mortality patterns.

\section{Materials and methods}

\section{BACKGROUND INFORMATION}

Nauru is an isolated island nation located in the Central Pacific. European contact with Nauru began in the 19th century and led to the development of phosphate mining by 1906 . Most of the income from phosphate went to the colonial powers who administered Nauru for the next 62 years. At the time of Nauru's independence in 1968, phosphate mining was a highly profitable operation and, because all proceeds then went to the Nauruans directly, it has led to considerable affluence among the island's indigenous population.

A change in lifestyle patterns from traditional to western among the Nauruan people began slowly with the advent of the phosphate mines, increased after the end of the second world war, and accelerated after independence. The rapid acquisition of affluence in Nauru has been unique among the experiences of 
developing countries and has subsequently increased the exposure of the population to a variety of risk factors for chronic disease. At present, Nauruans exhibit extraordinarily high prevalences of obesity, hypertension, glucose intolerance, cigarette smoking, and alcohol consumption. ${ }^{38-11}$ The prevalence of non-insulin-dependent diabetes mellitus (NIDDM) is $24 \%$, one of the highest in the world ${ }^{10}$ and uniquely identifies the Nauruan people, together with the Pima Indians of North America, ${ }^{12}{ }^{13}$ as a population at very high risk for the development of NIDDM.

\section{DATA COLLECTION AND VALIDATION}

In March 1986, a visit was made to Nauru and information on all deaths occurring in the island for the period 1982-5 inclusive was obtained by examining death certificates, hospital records, and patients' case notes. The data collected included date of death, age at death, sex, cause of death (direct, antecedent, and underlying causes), status at time of death, and place of death.

Where possible, information was cross-checked by comparison with other sources, for example the Catholic Church burial register and the Register of Births and Deaths. The Director of Medical Services in Nauru, who knew most of the cases personally, also validated the data.

\section{CODING}

Causes of death were assigned three digit rubrics according to the ninth revision of the International Classification of Diseases (ICD). ${ }^{14}$ In estimating diabetes mortality, the ICD criteria were applied regardless of whether diabetes was recorded as a cause of death or not - ie, in known diabetics, deaths due to complications of diabetes (renal failure, septicaemia, etc) were consistently classified as diabetic deaths.

Diabetic status at death was divided into two categories, 'diabetic' and 'not diabetic'. It was not always possible to determine diabetic status at death because diabetes was not consistently mentioned on death certificates when it was present in the subject, the register of diabetics in Nauru is not complete, and diabetes may have been present but not diagnosed at the time of death. An estimate of whether any misclassification of diabetic deaths occurred is included with the results.

\section{POPULATION ESTIMATES}

Censuses are conducted regularly in Nauru, the last being in May $1983 . .^{15}$ To estimate the mid-year population for each of the years 1982 to 1985 , the following method was used. A degree-five polynomial curve of exact fit was calculated for the graph of population against census year for the period 1952-83 (fig 1). The polynomial was then used to interpolate to

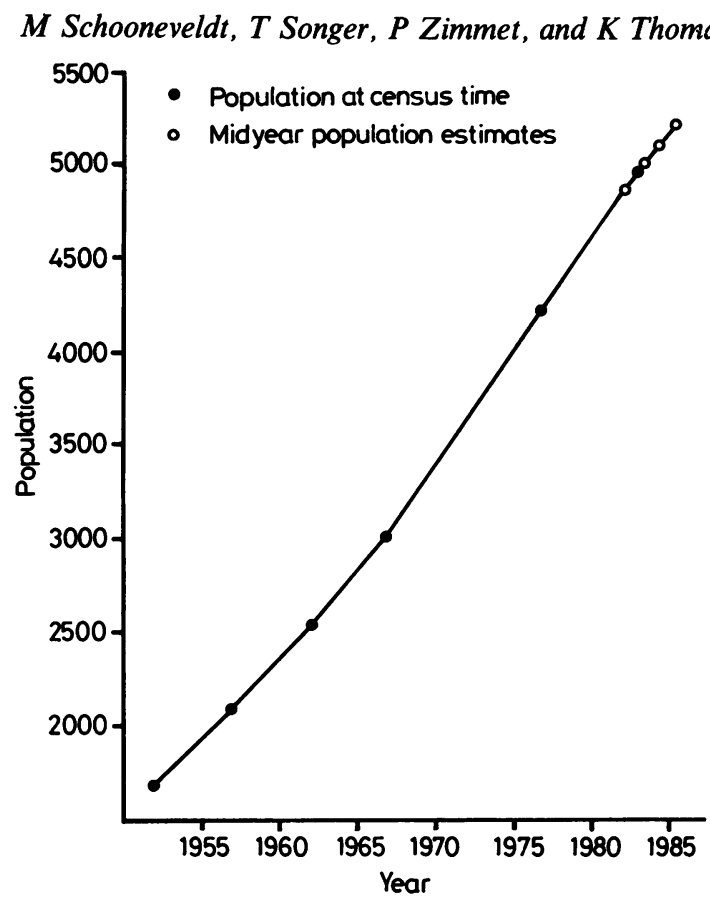

Fig 1 Midyear population estimates in Nauru 1982-5.

the mid-1982 population and to extrapolate to the population for each mid-year 1983 to 1985 . At least visually, the graph of population against census year is a smooth curve, and there is no reason to suppose that the trend it suggests has not continued.

The age-sex distribution for each year 1982-5 was estimated by assuming the distributions to be the same as the known distribution from the May 1983 census. This assumption was regarded as acceptable because the four year period $1982-5$ is comparatively short, and large changes in the age-sex distribution seem unlikely given the demography and geography of this island nation. In any event, total numbers of deaths in any age-sex category are small when compared to the total population in that category, and errors in population estimates are not expected to alter mortality rates very much.

For comparative purposes, age and sex specific mortality for Australia was calculated for the period 1982-4 using data supplied by the Australian Bureau of Statistics. ${ }^{16}$ At the time of writing, Australian mortality for 1985 was not available so that the Australian data cover only a three year period.

DATA ANALYSIS

On return from Nauru, data were keyed onto a Burroughs 7800 computer and checked, ready for processing. Mortality tables were calculated using the Statistical Package for the Social Sciences (SPSS). ${ }^{17}$ 
Abridged Life Tables were obtained by the method described by Elandt-Johnson and Johnson. ${ }^{18}$

For Nauruans in the age range 15-64 years, calculation of years of life lost through premature death from various causes was carried out by assuming a baseline life expectancy of 65 years, subtracting the age at death from 65 , and then summing over the various causes. This was done for diabetics and the population as a whole.

It was not considered feasible to calculate life expectancy for diabetics because the total number of cases was small.

\section{Results}

Table 1 shows all-cause mortality for the period $1982-5$, stratified by age group and sex. The crude death rates per annum per 1000 population were 18.5 for males and 10.3 for females. Apart from a small decrease in male rates from the 15-24 to the 25-34 year age group, mortality rates increased with age for both sexes.

The age-standardised mortality rate for Nauruan males was $19 \cdot 7$, and for females 9.8 per annum per 1000 population for the period $1982-5$ (table 2). When compared to the standardised rates for the period 1976-81 calculated from the study of Taylor and Thoma, ${ }^{3}$ the male rate showed no change; the female rate showed a small increase. The $1982-5$ rates were

Table 1 Nauru all-cause mortality by sex (1982-5) for persons 15 years and over.

\begin{tabular}{|c|c|c|c|c|c|c|}
\hline \multirow[t]{2}{*}{ Age (years) } & \multicolumn{2}{|c|}{ Males } & \multicolumn{2}{|c|}{ Females } & \multicolumn{2}{|l|}{ Total } \\
\hline & No. & $C M R^{*}$ & No & $C M R^{*}$ & No & $C M R^{*}$ \\
\hline $\begin{array}{l}15-24 \\
25-34 \\
35-44 \\
45-54 \\
55-64 \\
65+\end{array}$ & $\begin{array}{r}23 \\
16 \\
7 \\
16 \\
20 \\
17\end{array}$ & $\begin{array}{r}10.5 \\
10.1 \\
11.6 \\
28.4 \\
66.4 \\
178.9\end{array}$ & $\begin{array}{r}6 \\
8 \\
5 \\
11 \\
11 \\
15\end{array}$ & $\begin{array}{r}2.7 \\
5.1 \\
9.6 \\
20.3 \\
27.4 \\
102.7\end{array}$ & $\begin{array}{l}29 \\
24 \\
12 \\
27 \\
31 \\
32\end{array}$ & $\begin{array}{r}6.5 \\
7.6 \\
10.6 \\
24.4 \\
44.1 \\
132.8\end{array}$ \\
\hline Total & 99 & 18.5 & $56+$ & $10 \cdot 3$ & $155 t$ & 14.4 \\
\hline
\end{tabular}

In each subgroup, the number entered is the number of observed deaths.

* Crude mortality rate (CMR) per 1000 population per annum.

+ Total excludes 2 females for whom age at death was not known.

Table 2 Age-standardised mortality rates* $\uparrow$

\begin{tabular}{lccc}
\hline & Males & Females & Total \\
\hline Nauru 1982-85 & 19.7 & 9.8 & $14 \cdot 4$ \\
Nauru 1976-81 & 19.7 & 8.0 & 13.9 \\
Australia 1982-84 & 4.0 & 2.3 & 3.1
\end{tabular}

* Total Nauru population (age 15+ years) at risk 1982-85, by the direct method. $\dagger$ Per 1000 population per annum.
4.9 and 4.3 times the standardised rate for Australian males and females respectively.

Male : female age-specific mortality ratios for Nauruans are shown in figure 2. In all age groups, male mortality rates were higher than for females; in the 15-24 year age group, the male rate was almost four times higher.

Figure 2 also compares age and sex specific mortality in Nauru (1982-5) with that in Australia (1982-4). Apart from women aged 65 years and over, the Nauru rate for both males and females in all age

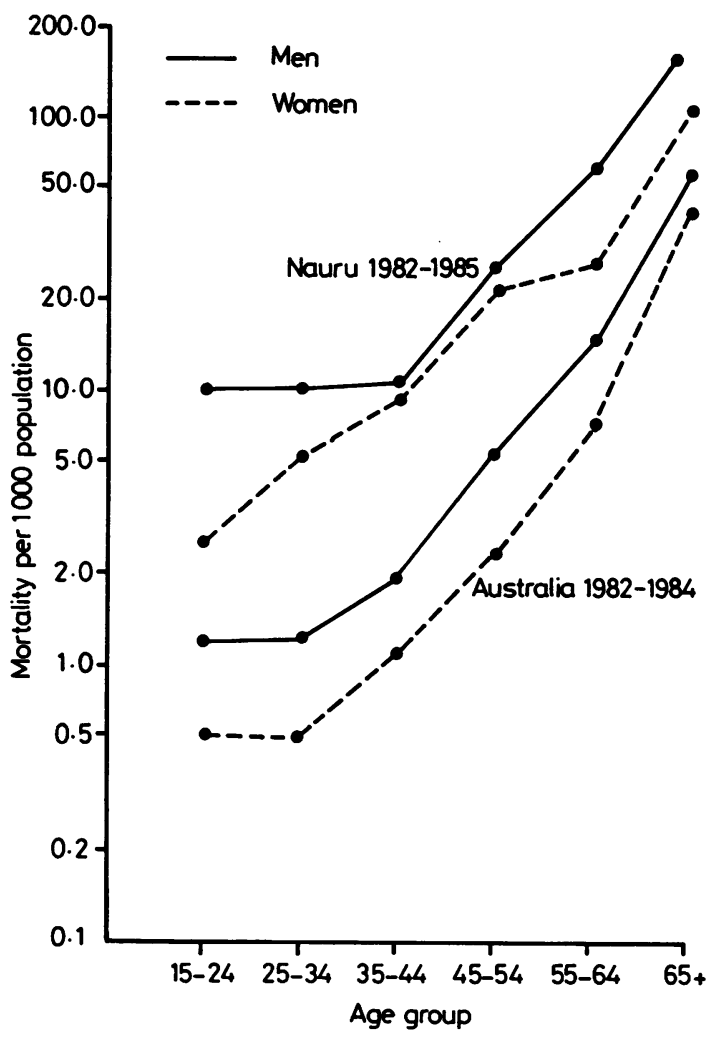

Fig 2 Age-specific mortality in Nauru and Australia

Mortality ratios.

Age group (years)

$15-24 \quad 25-34 \quad 35-44 \quad 45-54 \quad 55-64 \quad 65+$

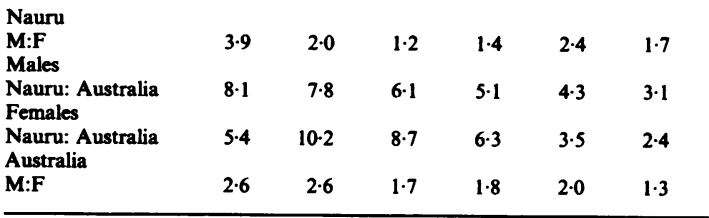


groups was over three times the Australian rate. In the 15-24 year age group for males, the rate was 8.1 times higher; in the 25-34 year age group for females it was $10 \cdot 2$ times higher.

Abridged life tables for Nauruan adults were calculated for the period 1982-5 and are shown in table 3. Life expectancies for a 15 year old male and female are 39.5 and 48.5 years respectively. Female life expectancy is more than five years longer than that for males at each exact age calculated except for 65 years.

Table 4 shows cause-specific mortality among nondiabetics and diabetics for the period 1982-5. To determine whether any misclassification of deaths in persons with diabetes occurred, we extrapolated from a cohort of the Nauru population (aged 20 years and over). ${ }^{5}$ Assuming the cohort to be representative of the general population, the expected number of deaths among those with diabetes and those without for the period 1982-5 for the whole population (aged 20 years and over) was estimated to be 72 and 50 respectively.
The actual numbers observed were 78 deaths in diabetics and 67 deaths in those without diabetes. To test for a difference between the observed and expected proportions of diabetic deaths, a standardised normal deviate of 1.19 (NS) was calculated, suggesting that little or no misclassification has occurred. In any event, errors in classification are likely to be on the side of underestimation of deaths among diabetics for reasons discussed earlier so that diabetes mortality would be greater than that observed.

Among males, the most common causes of death were circulatory system disorders $(33.3 \%)$, accidents $(25 \cdot 2 \%)$, and diabetes $(12 \cdot 1 \%)$. Among females, the most common causes were cancers (particularly of the lung and cervix) $(22.4 \%)$, circulatory system disorders $(20.7 \%)$, and diabetes $(17 \cdot 2 \%)$. The deaths attributed directly to diabetes were broken down as follows. Among males, $67 \%$ (8 deaths) were due to chronic renal failure and $25 \%$ (3 deaths) to diabetic septicaemia. One male death, attributed directly to

Table 3 Abridged life tables for Nauruan adults. Expectation of life at various ages and probability of dying during various intervals (given that subjects have survived to 15 years old).

\begin{tabular}{|c|c|c|c|c|c|c|c|}
\hline \multicolumn{3}{|c|}{$\begin{array}{l}\text { Expectation of life } \\
\text { (years) at various } \\
\text { ages* }\end{array}$} & \multicolumn{2}{|c|}{$\begin{array}{l}\text { Expected age at } \\
\text { death (years) }\end{array}$} & \multicolumn{2}{|c|}{$\begin{array}{l}\text { Probability of dying } \\
\text { during certain age } \\
\text { intervalst }\end{array}$} & \multirow{2}{*}{ Females } \\
\hline Exact age & Males & Females & Males & Females & Age intervals & Males & \\
\hline $\begin{array}{l}15 \\
25 \\
35 \\
45 \\
55 \\
65\end{array}$ & $\begin{array}{l}39.5 \\
32.9 \\
25.8 \\
18.5 \\
12.7 \\
10.3\end{array}$ & $\begin{array}{l}48 \cdot 5 \\
39 \cdot 7 \\
31 \cdot 5 \\
24 \cdot 1 \\
18 \cdot 2 \\
12 \cdot 1\end{array}$ & $\begin{array}{l}54.5 \\
57.9 \\
60.8 \\
63.5 \\
67.7 \\
75.3\end{array}$ & $\begin{array}{l}63 \cdot 5 \\
64 \cdot 7 \\
66 \cdot 5 \\
69 \cdot 1 \\
73 \cdot 2 \\
77 \cdot 1\end{array}$ & $\begin{array}{l}15-24 \\
25-34 \\
35-44 \\
45-54 \\
55-64 \\
65+\end{array}$ & $\begin{array}{l}0.0925 \\
0.0963 \\
0.1082 \\
0.2559 \\
0.5058 \\
1.0000\end{array}$ & $\begin{array}{l}0.0262 \\
0.0498 \\
0.0922 \\
0.1902 \\
0.2493 \\
1.0000\end{array}$ \\
\hline
\end{tabular}

* Conditional on having lived up to that age.

† Conditional on having lived up to that age interval.

Table 4 Causes of death for Nauruan adults (age 15+ years), by sex and diabetic status.

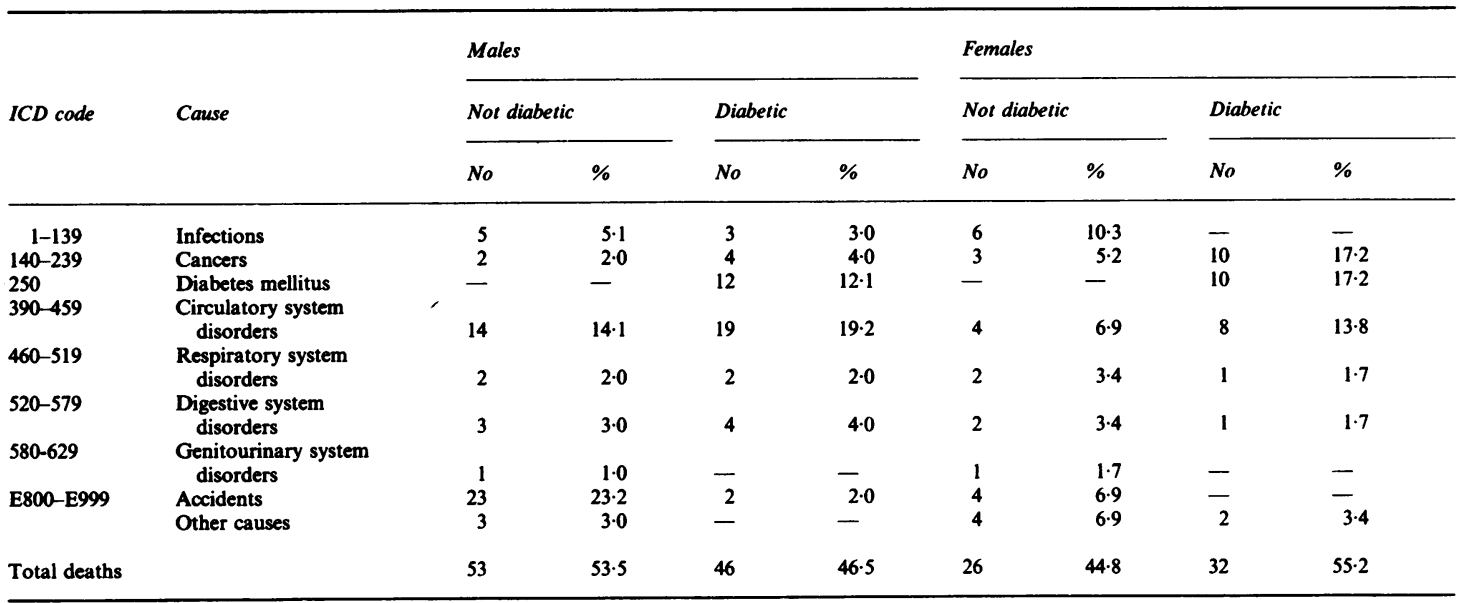


diabetes on the death certificate, could not be diagnosed further. Among females, $40 \%$ (4 deaths) were due to renal failure, and diabetic sepsis and diabetic ketoacidosis each resulted in $30 \%$ ( 3 deaths). Given inadequate laboratory facilities in Nauru, it is possible that the deaths from ketoacidosis were also due to septicaemia.

It is possible that among diabetics, their diabetes was a contributing factor in deaths coded as due to circulatory system disorders. When the deaths coded as due to diabetes and circulatory system disorders are combined for persons with diabetes, they account for $31.3 \%$ of all male deaths and for $31.0 \%$ of all female deaths. Mortality from heart disease, cardiac failure, and cerebrovascular disease made up the majority of deaths due to circulatory system disorders.

Overall, $46.5 \%$ of male deaths and $55.2 \%$ of female deaths were in known cases of diabetes. However, there was a large number of deaths from accidental causes among non-diabetic males. The majority $(68 \%)$ of male accidents involved motor vehicles and occurred in the 15-34 year age group. When accidental deaths are ignored, $59.5 \%$ of male deaths and $59.3 \%$ of female deaths were among diabetics.

The years of life lost through premature mortality for individuals who died within the ages 15-64 years are given in table 5 . Among males, $43.2 \%$ of all lost years were a consequence of accidents, $24.8 \%$ from circulatory system disorders, and $\mathbf{8 . 8 \%}$ from infections. Among females, infections (23.3\%), accidents $(19 \cdot 1 \%)$, and circulatory system disorders $(19.0 \%)$ accounted for the most years lost. The deaths among diabetics due to diabetes and circulatory system disorders combined accounted for $14.0 \%$ of the total years lost among males and for $26.0 \%$ among females. The total years lost among males is 2.4 times that for females.

\section{Discussion}

Mortality rates in the overall Nauruan population were extremely high. Age-standardised mortality rates were more than four times those reported in Australia. ${ }^{16}$ Nauruan males had higher standardised mortality rates than Nauruan females ( 19.7 versus $9 \cdot 8$ deaths per 1000 population per year), and the largest difference in mortality between the sexes occurred in the youngest age groups, particularly ages 15-24 years. In addition, average life expectancy at all ages was longer in females than in males.

These findings agree with those of Taylor and Thoma $^{3}$ who used similar methods to evaluate mortality during the period 1976-81. However, the present study shows a moderate increase in life expectancy for both Nauruan males and females. Despite this, the Nauruan life-span remains one of the lowest in the South Pacific ${ }^{3}$ and indeed the world. ${ }^{19}$

The increased rate of mortality in the Nauruan population appears to be related to three main factors: motor vehicle accidents, diabetes, and circulatory system disorders. Deaths due to motor vehicle accidents were markedly increased for males 15-34 years when compared to mortality in young Australian males ${ }^{16}$ and accounted for $45 \%$ of the total number of life-years lost due to premature mortality. Given that the island of Nauru is only $20 \mathrm{~km}$ in circumference and that the only proper road is a sealed one around the perimeter, the degree of accidental

Table 5 Premature mortality in Nauruans. Years of life lost through premature mortality in Nauruans aged 15-64 years, by cause of death, sex, and diabetic status.*

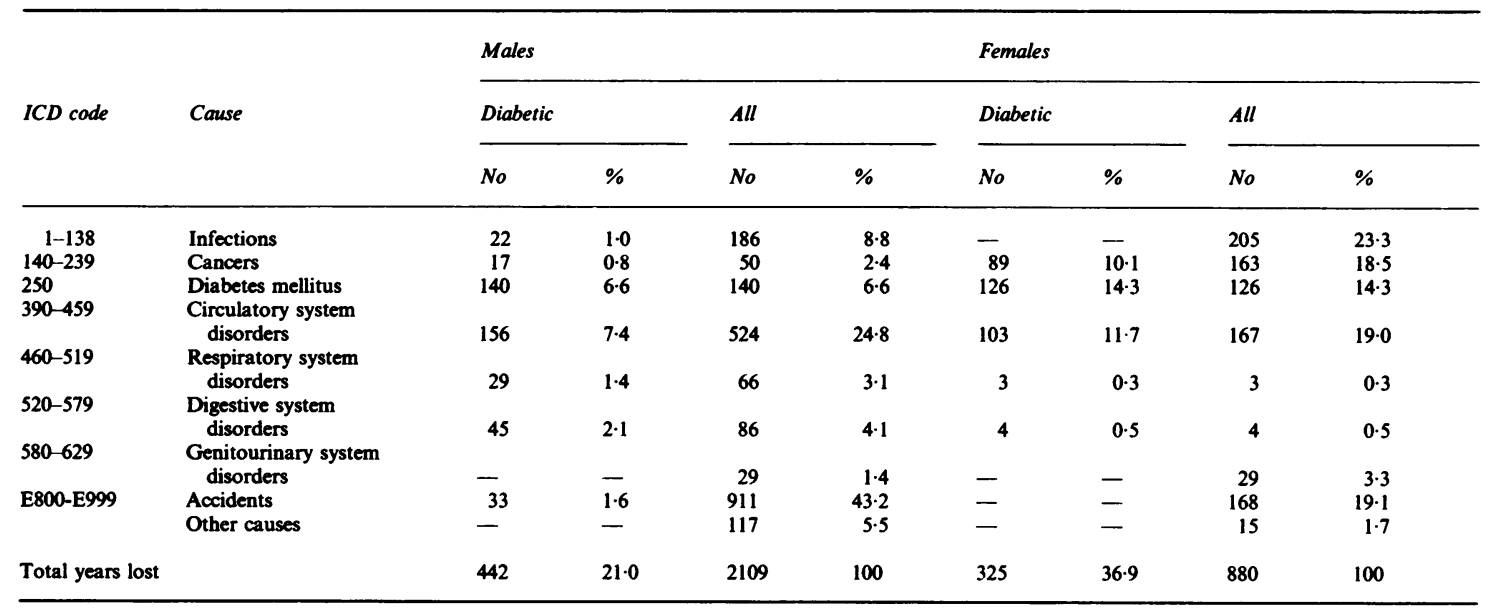

- Assuming a life expectancy of 65 years. 
mortality among males is remarkable. A review of the findings reported by Taylor and Thoma suggests that accidental death trends have remained high for Nauruan males over the last 10 years while mortality from motor vehicle accidents among females has fallen markedly from $20 \%$ of all deaths in $1976-81$ to $7 \%$ in 1982-5.

Mortality from diabetes and its related complications was another major contributor to the excess mortality seen. When mortality from accidents was excluded, almost $60 \%$ of the total deaths recorded in the population were among individuals with diabetes. This is high even after the high prevalence of diabetes in this community is taken into account. Premature mortality among Nauruan diabetics accounted for $21 \%$ of the total years of life lost in males and for $37 \%$ in females. Premature mortality among diabetics in Nauru has been reported recently by Zimmet et al. ${ }^{5}$ Similarly, other researchers ${ }^{20-24}$ have noted a high degree of premature death associated with NIDDM in other populations.

Circulatory system disorders contributed to the high mortality among Nauruans and were the leading cause of death for males, accounting for one third of all deaths, and the second leading cause of death for females. Premature mortality associated with these disorders was high, contributing to $32 \%$ of the life years lost in males and $31 \%$ in females. Diabetes is also likely to be a factor in the high prevalence of cardiovascular mortality in this population given previous findings that coronary heart disease occurs more frequently in diabetics than in non-diabetics, ${ }^{25}$ the high prevalence of diabetes in Nauru, and reports citing increased cardiovascular mortality among diabetics. 22 26-28

The results of the present study agree with the suggestion that mortality in the Nauru population reflects the long-term influence of westernisation. Mortality from both cardiovascular disease and diabetes mellitus has increased substantially from that reported for 1976-81.3 Similarly, deaths from neoplastic disorders have increased, particularly in Nauruan women for whom cancer was the leading cause of death in 1982-5. These changes are of considerable interest since deaths from these diseases were not in substantial numbers as recently as the second world war when deaths from infectious disease were the primary concern. ${ }^{6} 7$

Comparison of the current mortality patterns in Nauru with Australian data ${ }^{16}$ indicates that despite the increasing prevalence of mortality from cardiovascular disease and cancer in Nauru, current mortality from these diseases (in terms of the percentage of all deaths) is lower than that reported for Australia. It is quite reasonable, given the recent development of this island nation and the high prevalence of diabetes, to expect mortality rates for cardiovascular disease and indeed other noncommunicable diseases to increase.

Similar shifts in lifestyle and mortality patterns related to the westernisation of a nation have been noted recently in other South Pacific populations. Prior and Tasman-Jones ${ }^{31}$ have studied the recent history of morbidity and mortality in the New Zealand Maori. The Maori was introduced to western civilisation and economic practices and adopted these customs much earlier than the Nauruans. Similarly, the Maori initially showed high mortality from infectious diseases and later developed increased prevalences of cardiovascular disease, hypertension, and diabetes. Today, mortality from cardiovascular disease is the leading cause of death, particularly among females. ${ }^{31}$ The Australian Aboriginal population has undergone similar changes in lifestyle and mortality and now displays increased mortality from cardiovascular disease and diabetes mellitus. ${ }^{32} 33$

The mortality trends seen in Nauru suggest that westernisation has been a major factor influencing the change in health status of the population. It is becoming more apparent that the long-term exposure $\mathbb{D}$ to risk factors for western diseases in Nauruans has led $\stackrel{\oplus}{\Phi}$ 을 to a marked increase in the frequency of noncommunicable diseases. It is also likely that, in the absence of intervention, mortality from cardiovascular disease, diabetes, cancer, and motor vehicle accidents will continue to increase.

We thank Ms C Finch for data collection and statistical advice and Mrs S Fournel for typing. This study was funded by NIH Grant ROI AM 25446.

\section{References}

${ }^{1}$ Leading article. The epidemiological transition. Lancet 1977; ii: $670-1$.

2 Trowell H, Burkitt D (eds). Western diseases: their emergence and prevention. London: Edward Arnold 1981.

${ }^{3}$ Taylor R, Thoma K. Nauruan mortality 1976-1981 and a review of previous mortality data. South Pacific Commission, Noumea, New Caledonia April 1983.

4 Taylor R, Thoma K. Mortality patterns in the modernised Pacific island of Nauru. Am J Public Health 1985; 75: 149-55.

${ }^{5}$ Zimmet P, Finch C, Schooneveldt M, King H, Thoma K. Mortality from diabetes in Nauru - Results of a four-year follow-up. Diabetes Care 1987 (in press)

${ }^{6}$ Reports to the Council of the League of Nations on the Administration of Nauru. Printed and published by the Commonwealth of Australia, 1923-40.

${ }^{7}$ Reports to the General Assembly of the United Nations on the Administration of the Territory of Nauru. Printed and published by the Commonwealth of Australia, $1948-66$. 
${ }^{8}$ Zimmet P, Taft P, Guinea A, Guthrie W, Thomas K. The high prevalence of diabetes mellitus on a Central Pacific Island. Diabetologia 1977; 13: 111-5.

${ }^{9}$ Zimmet P, Jackson L, Whitehouse S. Blood pressure studies in two Pacific populations with varying degrees of modernisation. Nz Med J 1980; 91: 249-52.

${ }^{10}$ Zimmet $\mathbf{P}$, King $\mathrm{H}$, Taylor R, et al. The high prevalence of diabetes mellitus, impaired glucose tolerance and diabetic retinopathy in Nauru - the 1982 survey. Diabetes Research 1984; 1: 13-8.

11 Ringrose $\mathbf{H}$, Zimmet $P$. Nutrient intakes in an urbanized micronesian population with a high diabetes prevalence. Am J Clin Nutr 1979; 32: 1334-41.

12 Knowler WC, Bennett PH, Hamman RF, et al. Diabetes incidence and prevalence in Pima Indians: a 19-fold greater incidence than in Rochester, Minnesota. Am J Epidemiol 1978; 108: 497-505.

${ }^{13}$ Knowler WC, Pettitt DJ, Savage PJ, et al. Diabetes incidence in Pima Indians: contributions of obesity and parental diabetes. Am J Epidemiol 1981; 113: 144-56.

${ }^{14}$ World Health Organisation: Manual of the international classification of disease, injuries and causes of death. Vols I \& II. Ninth Revision Conference, 1975. Geneva, 1977.

${ }^{15}$ Census 1983 in the Republic of Nauru, Interim Report. Republic of Nauru: Department of Island Development and Industry.

${ }^{16}$ Australian Bureau of Statistics. Deaths Australia 1984, Catalogue No 3302.0.

${ }^{17}$ Nie N, Hull C, Jenkins J, Steinbrenner K, Bent D. SPSS statistical package for the social sciences, second edition. New York: McGraw-Hill. 1975.

${ }^{18}$ Elandt-Johnson R, Johnson N. Survival models and data analysis. Wiley, 1980.

19 The world almanac and book of facts, 1986. New York: Newspaper Enterprise Association.

${ }^{20}$ Pettitt DJ, Lisse JR, Knowler WC, Bennett PH. Mortality as a function of obesity and diabetes mellitus. Am J Epidemiol 1982; 115: 359-66.
${ }^{21}$ Sicree RA, Ram P, Zimmet P, Cabealawa S, King H. Mortality and health service utilization amongst Melanesian and Indian diabetics in Fiji. Diabetes Research and Clinical Practice 1985; 1: 227-34.

22 Goodkin G. Mortality factors in diabetes - a 20 year mortality study. J Occup Med 1975; 17: 716-21.

23 O'Sullivan JB, Mahan CM. Mortality related to diabetes and blood glucose levels in a community study. $\mathrm{Am} \mathrm{J}$ Epidemiol 1982; 116: 678-84.

24 WHO Technical Report Series, No 727, Diabetes mellitus (Report of a WHO Study Group). Geneva: World Health Organization, 1985.

${ }^{25}$ Zimmet P, King H. The epidemiology of diabetes mellitus. Chapter 1. The Diabetes Annual/2. Alberti KGMM, Krall LP (eds). Elsevier, 1986.

${ }^{26}$ Pan W, Cedres LB, Liu K, et al. Relationship of clinical diabetes and asymptomatic hyperglycemia to risk of coronary heart disease mortality in men and women. $\mathrm{Am}$ J Epidemiol 1986; 123: 504-16.

27 Ochi JW, Melton III LJ, Palumbo PJ, Chu C. A population-based study of diabetes mortality. Diabetes Care 1985; 8: 224-9.

28 The Carter Center of Emory University. Closing the gap: The problem of diabetes mellitus in the United States. Diabetes Care 1985; 8: 391-406.

${ }^{29}$ Zimmet P. Epidemiology of diabetes and its macrovascular manifestations in Pacific populations: the medical effects of social progress. Diabetes Care 1979; 21: 144-53.

30 Crewe DE, MacKeen PC. Mortality related to cardiovascular disease and diabetes mellitus in a modernizing population. Soc Sci \& Med 1982; 16: 175-81.

31 Prior I, Tasman-Jones C. New Zealand Maori and Pacific Polynesians. In Western diseases: their emergence and prevention. Trowell, Burkitt (eds). London: Edward Arnold, 1981.

32 Thomson N. Aboriginal health-current status. Aust NZ J Med 1984; 14: 705-17.

${ }^{33}$ Musgrave IA. Aboriginal mortality in Queensland. Med J Aust 1984; 140: 16-9.

Accepted for publication November 1987 